\begin{tabular}{|c|c|c|}
\hline UFG & 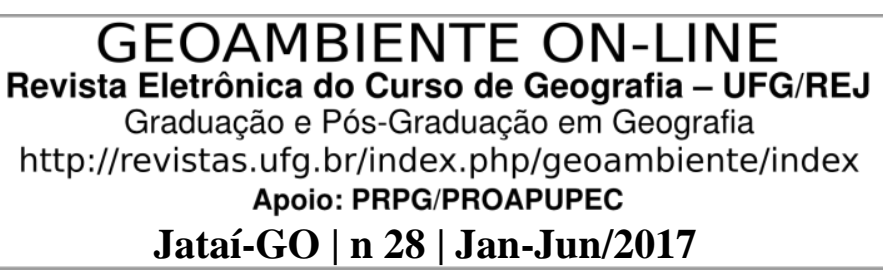 & $\begin{array}{l}\overbrace{0 \text { GEO }} \\
\text { ISSN } 1679-9860 \\
\text { ISAMBIENTE }\end{array}$ \\
\hline
\end{tabular}

\title{
MUSEU DE GEOCIÊNCIAS (UNICENTRO / CAMPUS IRATI): CONTRIBUINDO PARA A EDUCAÇÃO NÃO FORMAL E INCENTIVANDO A PESQUISA CIENTÍFICA E A VALORIZAÇÃO DO PATRIMÔNIO NATURAL Luiz Carlos Basso ${ }^{1}$, Ana Maria Charnei ${ }^{2}$, Ângela Guedes Moreira Lara ${ }^{3}$, Julio Manoel França da Silva ${ }^{4}$
}

(Universidade Estadual do Centro-Oeste do Paraná: 1 - Prof. Msc., Departamento de Geografia, bassolc4@gmail.com; 2 - Agente Universitária, Técnica de Laboratório, amcharnei@irati.unicentro.br; 3 - Profa. Espec., Departamento de Turismo, angelamlara@ hotmail.com; 4 - Prof. Dr., Departamento de Geografia, jmsilva@ unicentro.br)

Resumo: Este trabalho busca visa apresentar a trajetória do projeto Museu de Geociências da Universidade Estadual do Centro-Oeste do Paraná (UNICENTRO), Campus Irati, ao longo dos primeiros quinze anos de atividade com destaque para as ações educativas não formal de extensão universitária e pesquisa sobre o Patrimônio Natural de Irati e municípios circunvizinhos. Desde a sua criação, em 1997,o Museu iniciou coleção didática científica com exemplares taxidermizados da avifauna regional, fósseis, rochas e minerais. Desenvolveu exposições permanentes, temporárias, itinerantes, oficinas, minicursos, palestras e empréstimo de sua coleção didática para a comunidade estudantil, tendo atingido um público considerável, despertando a curiosidade e a consciência ambiental. Contanto com reserva técnica, laboratório de taxidermia, amplo acervo geológico (rochas, minerais e fósseis) e espaço expositivo próprio, o projeto, já institucionalizado academicamente, busca o credenciamento junto ao Conselho Estadual de Museus (COSEM), ampliando as parcerias e ações extensionistas.

Palavras-chave: Museu de Geociências, Projeto de extensão, Ensino de Geociências.

\section{MUSEUM OF GEOCIENCES (UNICENTRO / IRATI CAMPUS): CONTRIBUTING TO NON - FORMAL EDUCATION AND ENCOURAGING SCIENTIFIC RESEARCH AND THE VALUATION OF THE NATURAL HERITAGE}

Abstract: This papper aimed to bring up the main facts about the implementation path that UNICENTRO Geosciences Museum project in Irati campus went through, during its first

\footnotetext{
Artigo recebido para publicação em 15 de Dezembro de 2016

Artigo aprovado para publicação em 12 de Junho de 2017
} 


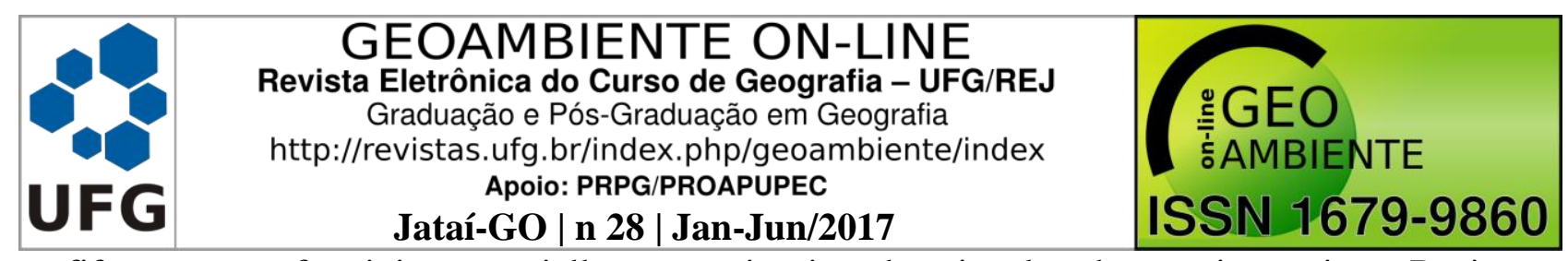

fifteen years of activity, especially concerning its educational and extension actions. During this time, the group in charge of the Museum started a scientific and didactic collection with taxidermy specimens of local birds and other animals, fossils, rocks and minerals. $\mathrm{He}$ developed activities such as permanent exhibitions, temporary, itinerant, workshops, minicourses, lectures and loan of his didactic collection for the student community, reaching a considerable audience, arousing curiosity and environmental awareness. Provided with technical reserve, taxidermy laboratory, large geological acquis (rocks, minerals and fossils) and exhibition space, the project, institutionalized in the university, Searching the accreditation by the State Council of Museums, expanding partnerships and actions extensionists.

Keywords: Geosciences Museum, Extension project, Geosciences teaching.

\section{MUSEO DE CIENCIAS DE LA TIERRA (UNICENTRO / CAMPUS IRATI): CONTRIBUIR A LA EDUCACIÓN NO FORMAL Y LA PROMOCIÓN DE LA INVESTIGACIÓN CIENTÍFICA Y LA VALORIZACIÓN DEL PATRIMONIO \\ NATURAL}

Resumen: Este trabajo tiene como objetivo dar a conocer los principales hechos de la trayectoria ejecución del proyecto de Museo de Ciencias de la Tierra UNICENTRO / Universidad Campus Irati durante los primeros quince años de actividad, con énfasis en las actividades de educación no formal de la extensión universitaria y la investigación sobre patrimonio natural. Desde su creación en 1997, el museo comenzó colección didáctica científica de los especímenes de taxidermia de aves regionales, fósiles, rocas y minerales. Actividades desarrolladas como exposiciones permanentes, temporales, viajes, talleres, minicursos, conferencias y prestando su colección didáctica para la comunidad estudiantil llegar a un público considerable, despertando la curiosidad y la conciencia ambiental. El trabajo se evalúa constantemente a través de la observación, el Museo cuenta con reserva técnica, laboratorio de taxidermia, y espacio de exposición. Actualmente, el proyecto ha logrado su institucionalización en UNICENTRO y buscar la acreditación con el Consejo Estatal de Museos.

Palabras-clave: Ciencias de la Tierra Museo Proyecto de Extensión Geoscience educación.

\section{Introdução}

O desenvolvimento de atividades educativas em ambientes diversificados visa 
despertar interesses e motivações que superam a mera apropriação dos conteúdos tradicionalmente abordados no contexto escolar. A prática de educação não formal, apesar de, em muitos casos, estar dissociada das práticas didático-pedagógicas, podem oportunizar ampla discussão de diversificadas áreas do conhecimento, propiciando, ainda, a comparação entre conteúdos formais e a realidade dos educandos.

Nesse sentido, as visitas e os trabalhos desenvolvidos nos museus estão se tornando um apoio à prática pedagógica nos diversos níveis de ensino; desde a educação infantil até o ensino superior em sentido interdisciplinar, com "todos os seus desafios epistemológicos, políticos e econômicos, (...) imprescindível no processo de comunicação e de educação que ocorre nos museus de ciências" (MARANDINO, 2005, p. 10); despertando "a consciência, a construção e reconstrução de concepções sobre o mundo" (BOMFIM, 2014, p. 13).

Como a função das instituições de ensino é formar cidadãos críticos, surge à necessidade de "parcerias com outras instituições e espaços" (TERÁN, 2013, p.2), complementando os ambientes formais de ensino. Queiroz (2013) considera que espaços alternativos são grandes aliados das escolas e universidades para a formação da cultura científica, contribuindo com as bases interpretativas da realidade como um todo pela sociedade, tornando-a mais ativa.

Jacobucci (2008) avalia que espaços alternativos de ensino vêm sendo adotados como objeto de estudo em pesquisas que buscam compreender as relações entre espaços nãoformais e formais no Brasil. Com este sentido, os museus e centros científicos têm sido apreciados pelo seu grande potencial de envolvimento da comunidade escolar com a cultura científica, destacando-se a realização de projetos de temática histórica, social, artística e ambiental.

Para o IPHAN/MinC (COSTA, 2006, p. 9) a definição de Museu inclui:
A presença de acervos e exposições colocados ao serviço da sociedade com o objetivo de propiciar à ampliação do campo de possibilidades da construção identitária, a percepção crítica da realidade, a produção de conhecimento e oportunidades de lazer (...) o desenvolvimento de programas, projetos e ações que utilizem o patrimônio cultural como recurso educacional, turístico e de inclusão social.

Em que pese à importância das suas origens históricas, o museu como entendemos atualmente tem suas raízes no Renascimento, período em que funcionava como "gabinetes de curiosidades" nos palácios da nobreza (SEPÚLVEDA, 2003, p.3). Estas exposições de objetos variados, embora restritos a grupos sociais de maior poder financeiro, influenciaram amplamente os museus atuais, inclusive, contribuindo ao desenvolvimento da ciência 


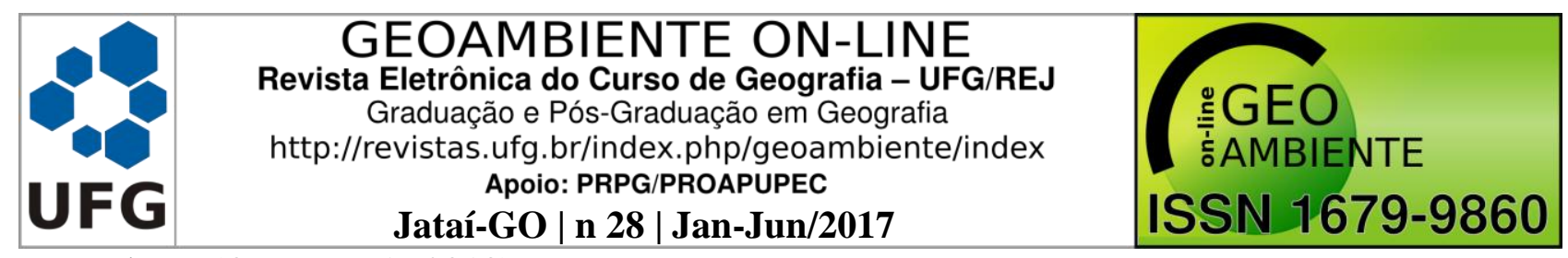

moderna (OLIVEIRA, 2010).

A concepção do museu como espaço educativo emerge no final do século XVII, objetivando atender "o espírito enciclopédico e as correntes educativas (...), enfatizando a necessidade de se colocar as coleções a serviço da educação do povo e dos artistas" (SEPÚLVEDA, 2003, p.4). No entanto, somente a partir do início do século XX o museu “passou a ser visto como um espaço perfeito para a união entre teoria e prática (...) aproximando-se do espaço laboratorial” (AZEVEDO, 2013, p.16); período em que os museus passaram a não se pautar, exclusivamente, nas classe sociais e nível de instrução intelectual.

Ao contrário dos séculos anteriores, onde os museus se restringiam ao zelo e tutela dos objetos pertencentes à determinada instituição, a nova museologia propõe, sobretudo, atendimento das perspectivas do público interessado. Esta conjuntura representa mudança radical de finalidade, sendo derivada da constatação de que "o papel social dos museus não pode ser dissociado da motivação de seus visitantes (...) - educação, aquisição de cultura, entretenimento ou divertimento"(SEPÚLVEDA, 2003, p. 8).

Segundo o Código de Ética para Museus (ICOM-BR, 2009), mencionado em Lima (2012, p. 43), "os acervos dos museus refletem o patrimônio cultural e natural das comunidades de onde provêm. Dessa forma, seu caráter ultrapassa aquele dos bens comuns, podendo envolver fortes referências a identidade nacional, regional, local, étnica, religiosa ou política”.

A interação da comunidade e a promoção do seu patrimônio fazem parte do papel socioeducativo do museu, uma vez que os acervos refletem a história natural e cultural das comunidades ao seu redor (COSTA, 2006), sendo intrínseca a relação entre museu e educação, destacando-se o uso do acervo preservado pela sociedade (SANTOS, 1993). Isso implica em estruturar os espaços físicos para viabilizar a interação da pesquisa científica com a comunidade onde ela se insere (BARRETO, 2003).

Com base no exposto, é perceptível o crescimento do potencial educativo dos museus, considerando o contexto evolutivo das atividades propostas e desenvolvidas pelos mesmos. Assim, oficinas, exposições interativas e projetos educativos são atividades cada vez mais presentes nas suas agendas (FIGURELLI, 2011), redefinindo estratégias no contexto formal ou informal de ensino, indicando, portanto, panoramas favoráveis de aplicabilidade.

Partindo de um viés extensionista, o presente artigo busca apresentar, suscintamente, as principais contribuições do Museu de Geociências da Universidade Estadual do CentroOeste (UNICENTRO), Campus Irati, através de ações extensionistas desenvolvidas a partir de 
1997 - ano de sua fundação. Esta instituição pública de ensino, que recebe estudantes de diferentes cidades do Brasil, está localizada no município paranaense de Irati, por sua vez, distante cerca de $150 \mathrm{~km}$ da capital do Estado, Curitiba (Figura 1).

Figura 1 - Localização do município de Irati (PR)

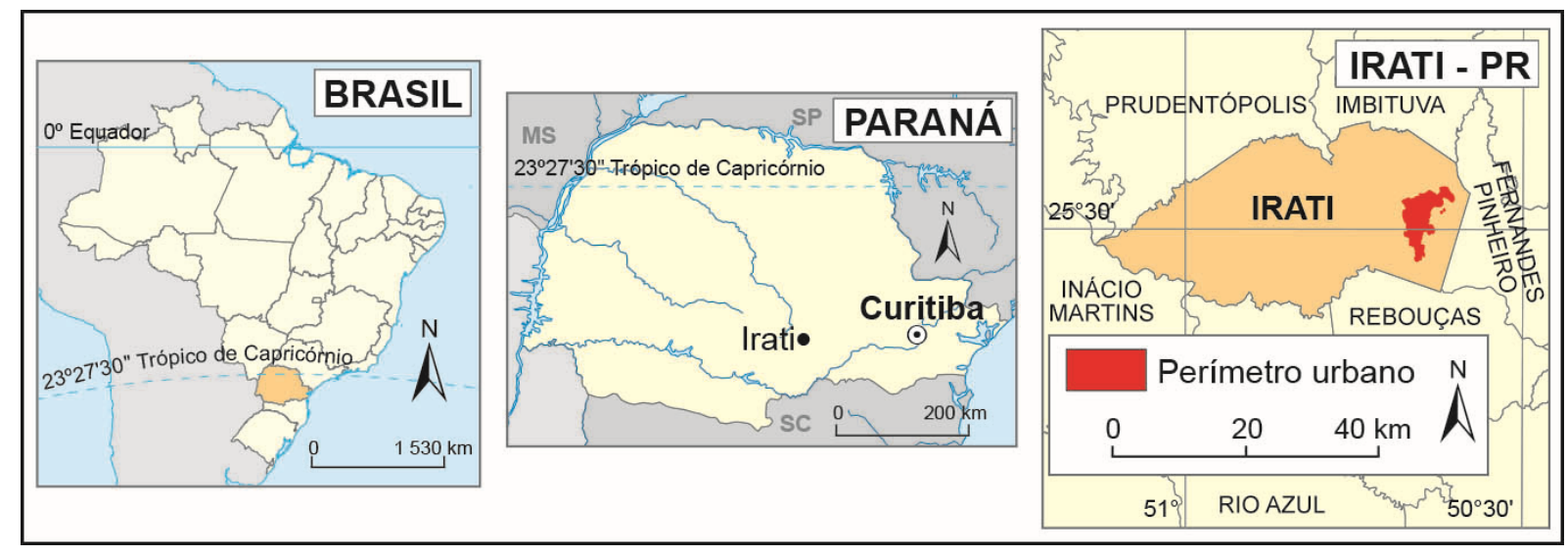

Organização: Próprio autor

\section{Histórico do Museu de Geociências da UNICENTRO/Campus Irati}

A antiga Fundação Faculdade de Educação, Ciências e Letras de Irati (FECLI), hoje UNICENTRO, criada em 1974 onde ofereciam, na época, cursos de Licenciatura, em Pedagogia, Letras Português/Inglês e Ciências, atendendo o município de Irati e região. Após longo percurso, com a incorporação da FECLI e da Faculdade de Filosofia, Ciências e Letras de Guarapuava (FAFIG), em agosto de 1997, é reconhecida a Universidade Estadual do Centro-Oeste (UNICENTRO) com sede em Guarapuava e Campus na cidade de Irati.

Neste contexto, o projeto do Museu de Geociências da UNICENTRO/Campus de Irati foi estruturado como um projeto de extensão permanente. O projeto foi aprovado oficialmente pelo em 22 de maio de 1997, pela resolução $N^{\circ} 088 / 97$, e sediado no Departamento de Ciências Exatas e Naturais da Instituição, hoje extinto, sob direção de Campus da professora Luíza Nelma Fillus.

O Centro Universitário de Irati está localizado no Bairro Riozinho, no antigo Seminário Santa Maria, a $8 \mathrm{~km}$ da sede do município, em meio a uma área remanescente da Floresta com Araucária e um afloramento de folhelho onde encontramos uma grande quantidade de fósseis o qual denominamos de Sítio Paleontológico.

Estes também foram fatores que contribuíram para a idealização e elaboração do projeto do Museu que tinha inicialmente como objetivo montar um acervo de caráter didático 

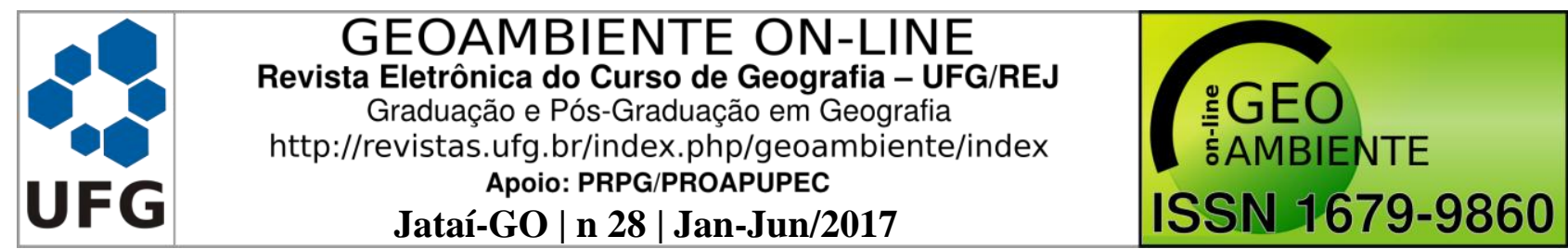

com amostras de material biológico, geológico e paleontológico, destinado às aulas práticas do curso de Ciências Licenciatura, sendo os mesmos pertencentes a professores da instituição.

O projeto previa a utilização de duas salas no prédio principal do Campus, uma para acondicionar o acervo em crescimento e outra para exposições, além dos laboratórios de Geofísica, Zoologia e Botânica para preparo de material, com a participação de dois monitores. Por solicitação da Assessoria de Planejamento da UNICENTRO, foi elaborado um regulamento para utilização do acervo do museu que previa condições para empréstimo e penalidades, além de estabelecer um horário de funcionamento. Na previsão orçamentária os proponentes solicitavam a aquisição de 20 mesas expositoras com vitrines e material de consumo a serem adquiridos pela UNICENTRO, onde foi emitido o parecer de Execução Orçamentária e Contábil, em 21/03/1997 que o projeto deveria ser autossustentável.

Houve a necessidade de elaboração de novo projeto, visando angariar recursos imprescindíveis para a implantação das bases estruturais do museu. Intitulado "Projeto Piloto para Instalação de Recipientes para Coleta Seletiva de Lixo na UNICENTRO/Campus Irati”, foi derivado de pesquisa de alunos do curso de Engenharia Florestal, na disciplina de Educação Ambiental. Este projeto tinha cunho informativo, envolvendo toda comunidade acadêmica. Para tanto foi celebrado um Termo de Compromisso entre o Centro Universitário de Irati, a Associação de Professores e Funcionários da UNICENTRO e o Diretório Estudantil.

Conforme os primeiros itens do Termo de Compromisso, aprovado em assembléia e assinado em 23 de junho de 1997, a Associação de Professores e Funcionários se responsabilizaria pela venda do papel reciclável coletado nas instalações da Instituição de acordo com o projeto "Coleta Seletiva de Lixo"; quanto ao produto da venda desse material, $75 \%$ do total arrecadado seriam revertidos ao Museu de Geociências, 20\% ficaria no caixa da Associação de Professores e Funcionários e os 5\% restantes seriam repassados ao Diretório Estudantil. Além do papel, com o tempo, o Museu se beneficiou com a venda de outros materiais recicláveis. O acordo permaneceu vigente até o ano de 2008, quando a Comissão Ambiental do Campus assumiu o gerenciamento dos resíduos sólidos produzidos na Universidade, destinando-os à Cooperativa de Agentes Ambientais Catadores de IratiCOCAIR.

Esta parceria é considerada o ponto de partida para implantação do projeto do Museu de forma autossustentável, e que possibilitou a realização de atividades previstas nos cronogramas. Com os recursos repassados ao Museu foi possível efetuar aquisições de 


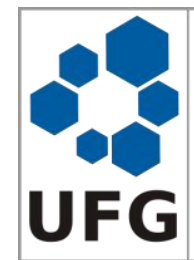

\section{GEOAMBIENTE ON-LINE \\ Revista Eletrônica do Curso de Geografia - UFG/REJ \\ Graduação e Pós-Graduação em Geografia \\ http://revistas.ufg.br/index.php/geoambiente/index \\ Apoio: PRPG/PROAPUPEC \\ Jataí-GO | 28 | Jan-Jun/2017}

material de uso permanente e de consumo.

É importante destacar o papel do Diretório Estudantil na mobilização dos acadêmicos nos dois primeiros anos do projeto de Coleta Seletiva de Lixo por meio de gincanas de calouros e outras atividades de educação ambiental; esse movimento arrecadou aproximadamente 21 toneladas de papel que foram destinadas à reciclagem em empresa situada no município vizinho de São Mateus do Sul.

Em 1994 o Campus recebeu a doação de uma antiga edificação construída segundo os moldes da arquitetura paranaense. O imóvel pertencia à família Anciutti - descendentes dos primeiros colonizadores italianos que chegaram à região e residentes no bairro Riozinho desde 1907 (comunicação oral de Madalena Maria Anciutti Orreda).

O espaço, segundo solicitação dos doadores, deveria acomodar um museu rural, com peças cedidas pela comunidade, que representassem a cultura local. Esta proposta não foi levada adiante e em 1998 a casa foi cedida ao Museu de Geociências para realização de exposições. Essa edificação foi retirada do seu local de origem e reconstruída em meio a um bosque (Figura 2), próximo a outros atrativos como gruta e trilhas e que representa, junto (Figura 3) o prédio principal do Campus, importante registro de um patrimônio a ser preservado.

Figura 2 - Sede do Museu de Geociências

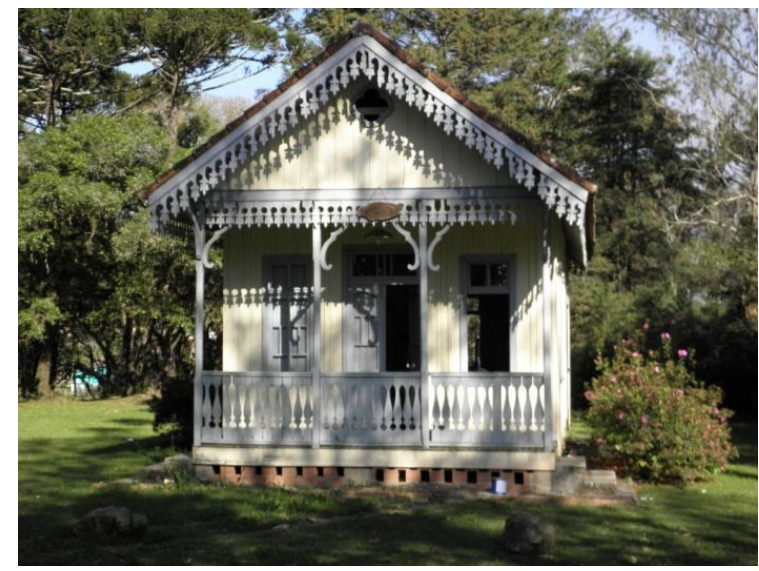

Fonte: Próprio autor
Figura 3 - Prédio histórico da universidade

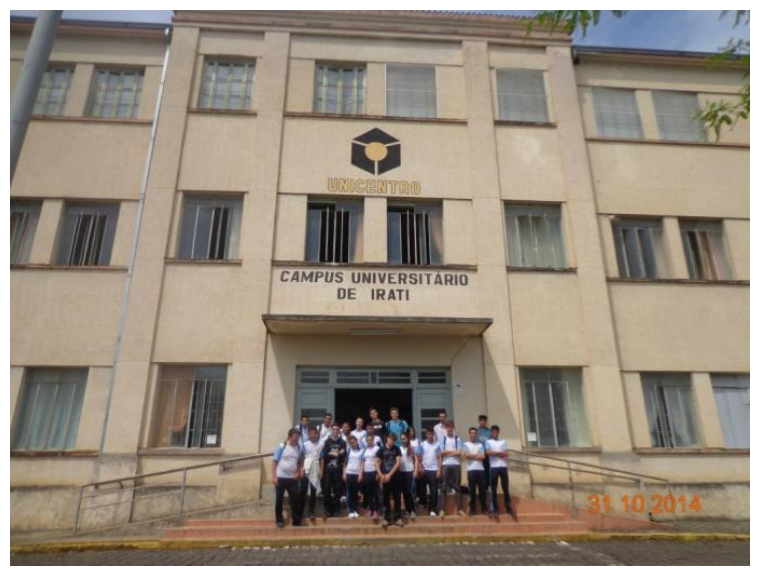

Fonte: Próprio autor

Desde o princípio de suas atividades o Museu de Geociências da UNICENTRO/Campus de Irati contou com parcerias. A primeira delas com a Associação de Professores e Funcionários da UNICENTRO como mencionado anteriormente. Outro parceiro que sempre apoiou o projeto foi à empresa "Caminhos do Paraná" que recolheu e enviou ao laboratório de taxidermia animais mortos por atropelamento na rodovia Irati /Guarapuava (BR 


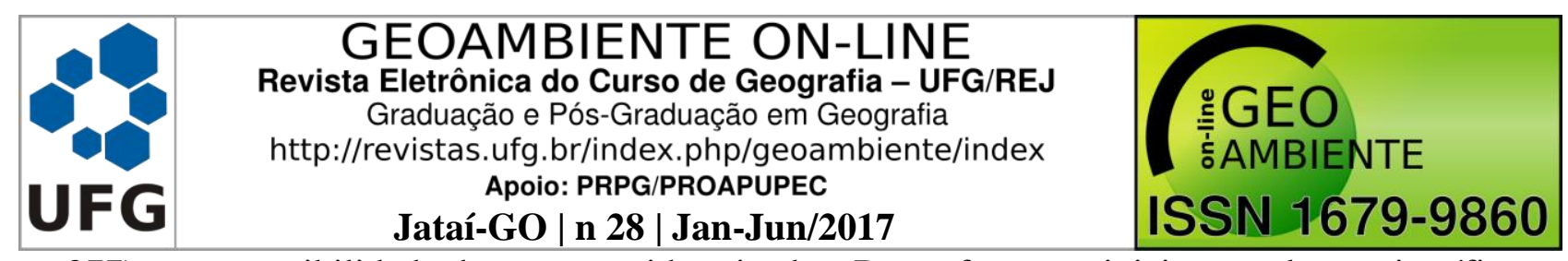

277), com possibilidade de serem taxidermizados. Dessa forma se iniciou a coleção científica de vertebrados do Museu, com espécimes representativos da fauna regional (Figura 4), complementada, posteriormente, por parcerias institucionais (Floresta Nacional de Irati e Instituto Ambiental do Paraná).

Figuras 4 - Animais taxidermizados pertencentes à coleção do Museu.

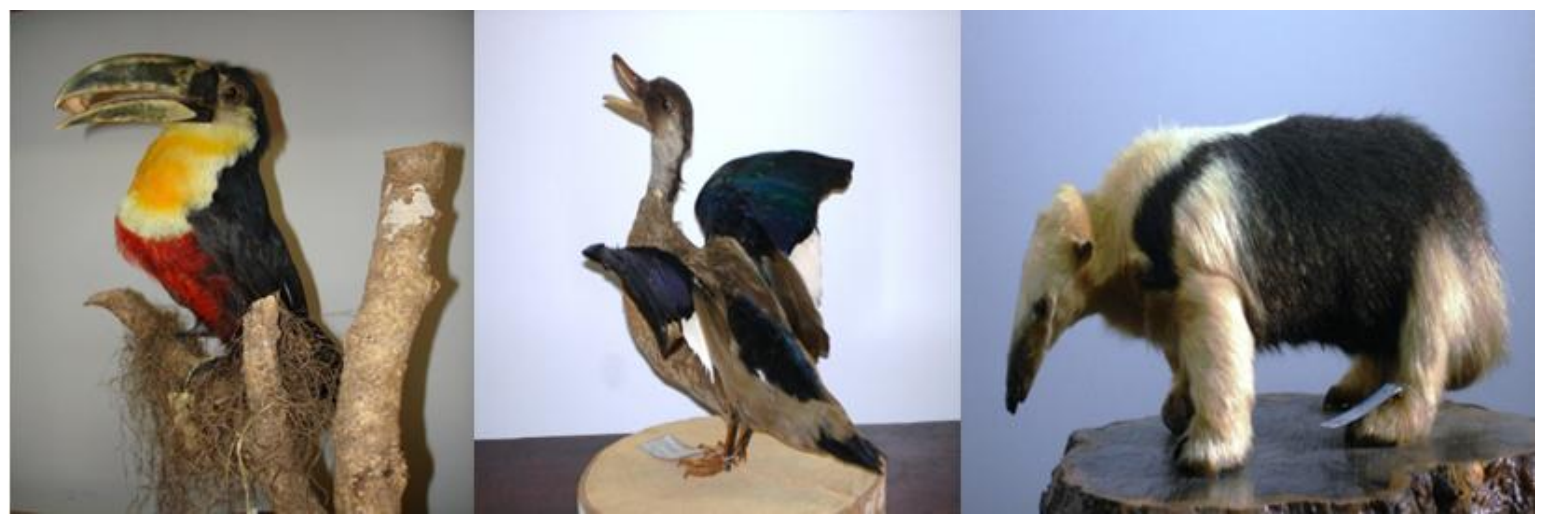

Fonte: Próprio autor

A equipe do Museu de Geociências, por seu lado, também presta serviços à Unidade de Conservação mencionada, realizando periodicamente a conservação preventiva do acervo do Museu da FLONA. Também são realizadas permutas temporárias de exemplares taxidermizados das coleções do Museu de Geociências da UNICENTRO e do Museu da FLONA visando enriquecer as exposições temáticas voltadas para a comunidade em geral ofertada em ambas as Instituições.

Ainda no campo das parcerias devemos mencionar o Museu de História Natural do Capão da Imbuia (MHNCI), em Curitiba, local onde foi realizado treinamento em técnicas de taxidermia e identificação de lotes de ofídios e crânios de vertebrados.

Dentro do Campus, o Museu de Geociências tem contado com a colaboração do Herbário da UNICENTRO/HUCO desde sua fundação (2001), por meio da disponibilização de material botânico para exposições como exsicatas e realização de palestras e minicursos de interesse comum em atividades previstas pelo cronograma anual.

Em 2011, uma nova parceria se estabeleceu com o Departamento de Turismo mediante o projeto "Turismo Receptivo e Pedagógico na UNICENTRO/Irati”, abordando a universidade como um espaço físico de produção e democratização do conhecimento científico. Os atrativos ofertados fazem parte de um roteiro (Figura 5) abrangendo: Reserva Técnica, Trilha da Gruta, Sitio Paleontológico do Campus Universitário de Irati e 


\begin{tabular}{|c|c|c|}
\hline UF & $\begin{array}{c}\text { GEOAMBIENTE ON-LINE } \\
\text { Revista Eletrônica do Curso de Geografia - UFG/REJ } \\
\text { Graduação e Pós-Graduacão em Geografia } \\
\text { http://revistas.ufg.br/index.php/geoambiente/index } \\
\text { Apoio: PRPG/PROAPUPEC } \\
\text { Jataí-GO |n } \mathbf{2 8} \mid \text { Jan-Jun/2017 }\end{array}$ & $\begin{array}{l}\text { :GEO } \\
\text { ISSN } 1679-9860\end{array}$ \\
\hline
\end{tabular}

afloramentos de folhelho betuminoso em pedreira desativada, dentro do campus, onde se encontra a maior parte da coleção in situ de rochas, fósseis e minerais.

Figuras 5 - Roteiros ofertados pelo Museu de Geociências: A) Reserva técnica, B) Trilha da Gruta, C) Sítio Paleontológico e D) Afloramento de Folhelho Betuminoso.
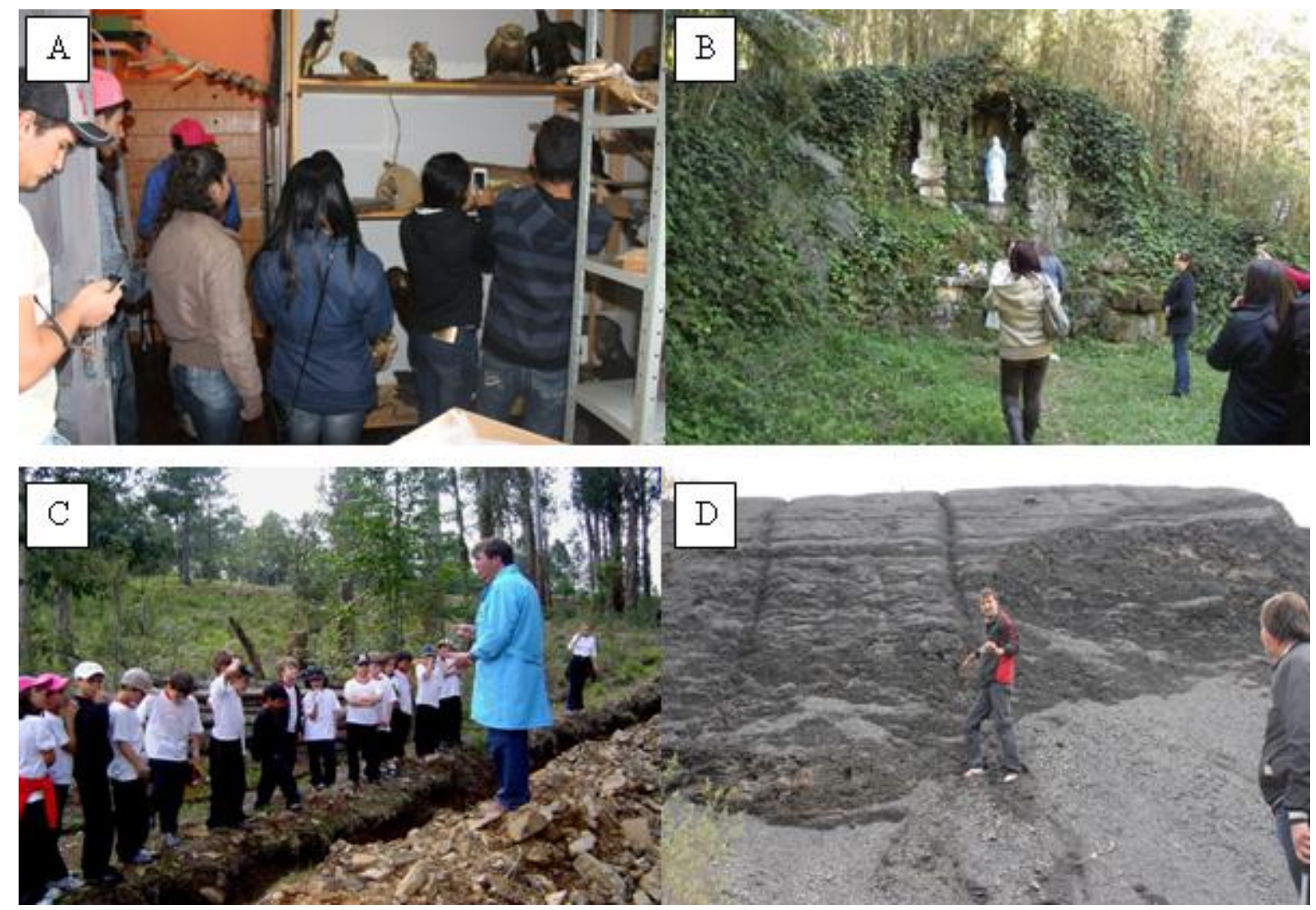

Fonte: Próprio autor

\section{Objetivos do Museu de Geociências}

O Museu de Geociências foi inicialmente idealizado como um museu didático, objetivando, inicialmente, atender a comunidade estudantil. No entanto, diante da perspectiva de crescimento da universidade e inserção no ensino, pesquisa e extensão, os objetivos foram ampliados e atualizados.

Atualmente, o objetivo geral refere-se ao desenvolvimento de ações que visem a adoção do patrimônio cultural e natural como recurso educacional, visando sua preservação, enquanto os objetivos específicos vislumbram:

- Contribuir para o ensino da zoologia, ecologia, educação ambiental, paleontologia, geologia, biogeografia nos cursos de Geografia, Turismo, Pedagogia, Engenharia

Florestal e Engenharia Ambiental; 


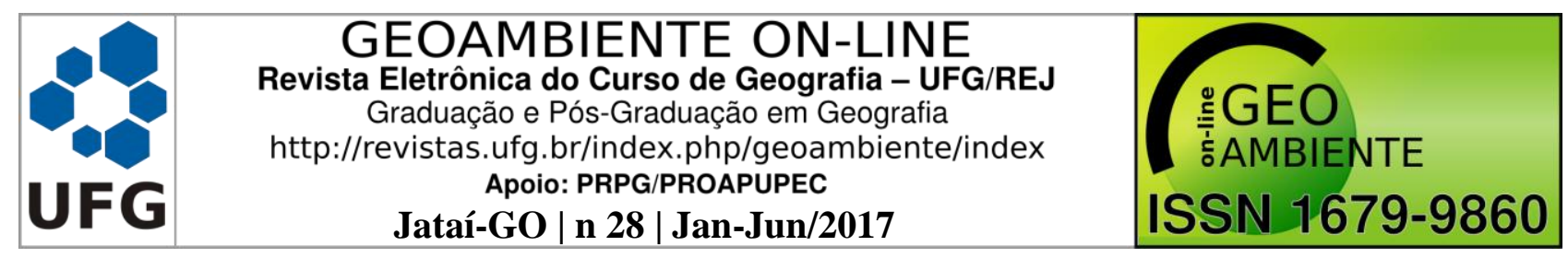

- Aplicar a pesquisa zoológica em trabalhos de levantamentos zoológicos, estudos de distribuição de fauna, biossistemática, polinização e dispersão;

- Contribuir para coleção zoológica e paleontológica da região Centro-sudeste e Sul do Paraná, sua distribuição geográfica e a preservação da fauna regional;

- Contribuir, na forma de intercâmbio, com os demais museus estaduais e nacionais;

- Atender as consultas da comunidade em geral, especialmente às pessoas ou entidades envolvidas em estudos preservacionistas ou de educação ambiental;

- Proporcionar treinamento em manejo de museu a acadêmicos através de estágios diversos;

- Organizar coleções científicas e didáticas;

- Realizar exposições temporárias e itinerantes, palestras, oficinas e minicursos.

\section{Procedimentos metodológicos do Museu de Geociências}

O Museu realizou aquisição e disponibilização de material biológico, geológico e paleontológico para uso em laboratório, salas de aula, exposições e Feiras de Ciências por meio de doações de acadêmicos e da comunidade, além de materiais coletados durante a realização de viagens de estudos e aulas de campo. Quanto ao preparo e identificação de material, as peças doadas e/ou coletadas são avaliadas quanto ao valor didático e científico, sendo então encaminhadas para identificação e conservação de acordo com as técnicas adequadas.

É considerada atividade de caráter permanente no Museu o atendimento às escolas públicas e privadas de Irati e região, instituições como SENAR, SENAI e SESI e comunidade em geral. Esse trabalho abrange atividades como: a) classificação, organização e manutenção de coleções didáticas em laboratórios das escolas da rede de ensino da região; b) empréstimo de exemplares da coleção didática do museu; c) empréstimo e doação de kits didáticos; d) exposições monitoradas; visitas à reserva técnica, laboratório de taxidermia, sítio paleontológico e laboratório de Geologia; e e) atividades de educação ambiental, interpretação de trilhas, oficinas de maquetes, minicursos e palestras.

Por meio de exposições, oficinas, minicursos e empréstimo de exemplares da coleção para aulas práticas, o museu vem atendendo sistematicamente professores e alunos dos cursos de Geografia, Engenharia Florestal, Pedagogia, Turismo; acadêmicos da UNICENTRO em período de Estágio Supervisionado; alunos da Universidade Aberta da Terceira Idade; e acadêmicos e professores de outras instituições de ensino. 
Desde sua implantação o projeto programou a montagem de duas exposições de caráter permanente, exposições temporárias e itinerantes. As exposições são realizadas em diferentes espaços expositivos dentro e fora do âmbito da Universidade, como o "Museu do Bosque", biblioteca, departamentos e áreas internas de maior circulação do prédio principal. Fora do Centro Universitário o Museu montou exposições na Casa da Cultura de Irati, Caixa Econômica Federal, Clube do Comércio, escolas e feiras locais e regionais.

O Quadro 1 expõe a lista de exposições, período de execução e número aproximado de visitantes; enquanto o Quadro 2 indica a coleção científica de animais taxidermizados.

Quadro 1 - Exposições realizadas pelo Museu de Geociências entre 1997 e 2015.

\begin{tabular}{|l|c|c|c|}
\hline \multicolumn{1}{|c|}{ Título } & $\begin{array}{c}\text { Modalidade } \\
\text { da Exposição }\end{array}$ & Período & $\begin{array}{c}\mathbf{N}^{\mathbf{0}} \text { aproximado } \\
\text { de Visitantes }\end{array}$ \\
\hline $\begin{array}{l}\text { Mesosaurus brasiliensis - Patrimônio de } \\
\text { Irati/PR }\end{array}$ & Itinerante & $1997 / 2012$ & 5000 \\
\hline Fósseis, Rochas e Minerais & Permanente & $1997 / 2012$ & 6700 \\
\hline Conchas do Litoral Brasileiro & Temporária & 1997 & 4000 \\
\hline A Natureza através dos Tempos Geológicos & Temporária & 1998 & 1640 \\
\hline Ilha do Mel e seus Ecossistemas & Temporária & 2004 & 2000 \\
\hline $\begin{array}{l}\text { O Significado de uma Bioexposição no } \\
\text { Aprendizado da Botânica }\end{array}$ & Temporária & $2005 / 2006$ & 1720 \\
\hline Mesosaurus brasiliensis e o Permiano & Temporária & 2009 & 500 \\
\hline Eras Geológicas & Temporária & 2009 & 480 \\
\hline $\begin{array}{l}\text { Exposição Interativa "Meliponídeos Nossas } \\
\text { Abelhas Nativas sem Ferrão" }\end{array}$ & $\begin{array}{c}\text { Temporária } \\
\text { Itinerante }\end{array}$ & $2009 / 2010 /$ & 3000 \\
\hline Os Animais e a Floresta com Araucaria & Temporária & $2011 / 2012$ & 715 \\
\hline Exposição “Tesouros do Mar” & Temporária & 2015 & 460 \\
\hline
\end{tabular}

Elaboração: Próprio autor

Quadro 2-Animais taxidermizados disponíveis na reserva técnica até 11/2015

\begin{tabular}{|l|c|c|c|c|c|}
\hline Filo/Postura & Mammalia & Aves & Reptilia & Pisces & Total \\
\hline Postura natural & 28 & 51 & 9 & 5 & 93 \\
\hline Postura científica & 3 & 36 & - & - & 39 \\
\hline Total & 29 & 81 & 9 & 5 & 132 \\
\hline
\end{tabular}

Fonte: Registros da reserva técnica

Cabe destacar, finalmente, que os integrantes do Museu de GeociênciasUNICENTRO, vêm oferecendo periodicamente oficinas, exposições, palestras e minicursos em eventos realizados em diversificadas instituições.

A divulgação dos resultados, por sua vez, é viabilizada em eventos e periódicos científicos, ampliando a divulgação dos trabalhos desenvolvidos e oportunizando a atualização teórica e metodológica das temáticas envolvidas. 


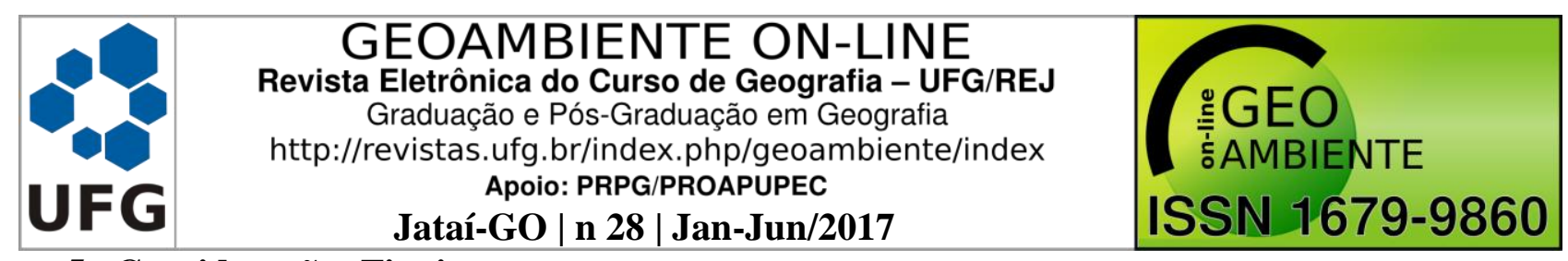

\section{Considerações Finais}

- O trabalho de constituição do projeto Museu de Geociências da UNICENTRO/Campus Universitário de Irati decorreu-se ao longo de muitos anos, concomitantemente ao crescimento da própria universidade.

- Atualmente vislumbra-se atender as recomendações do Conselho Internacional de Museus - ICOM, estruturando-se como uma instituição permanente, sem fins lucrativos, aberta ao público, que visa a conservação, pesquisa e exposição de coleções de objetos de caráter cultural ou científico para fins educativos ou mero entretenimento, amparado institucionalmente em caráter permanente.

- Considerando as ações didático-pedagógicas e o comprometimento com o ensino, a pesquisa e a extensão, considera-se que trabalho integrado e as parcerias institucionais, podem fortalecer a interdisciplinaridade, propiciando a democratização de conhecimentos científicos oriundos da universidade, ampliando, em última instância, suas funções educacionais e socioambientais.

\section{Referências}

AZEVEDO, M. D. P. Conservação de coleções geológicas utilizando o acervo do Museu de Geociências da USP. Dissertação de Mestrado. São Paulo, 2013

BARRETO, M. Turismo e legado cultural. Campinas: Papirus, 2003.

BOMFIM, S.R.M. Espaço educativo não formal: práticas na escola pública. Monografia, 2014. Disponível: <www.ffp.uerj.br/arquivos/dedu/monografias/20142/SRMB-2014>. Acesso: 10 dez. 2015.

COSTA, E. P. Princípios básicos da Museologia. Curitiba: Secretaria de Estado da Cultura; 2006.

FIGURELLI, G.R. Articulações entre educação e museologia e suas contribuições para o desenvolvimento do ser humano. Revista do PPG-PMUS, vol. 4 n. 2, 2011. Disponível: <www.revistamuseologiaepatrimonio.mast.br/index.php/ppgpmus/article/viewFile/208/169>.

Acesso: 04 jan. 2016.

JACOBUCCI, D.F.C. Contribuições dos espaços não-formais de educação para a formação da cultura científica. Revista Em Extensão v. 7, 2008.

LIMA, D.F.C. Museologia-Museu e Patrimônio, Patrimonialização e Musealização: ambiência de comunhão. Boletim do Museu Paraense Emílio Goeldi Ciências Humanas. v.7, n.1, p.31-50, jan-abr, 2012. Disponível: <www.scielo.br/pdf/bgoeldi/v7n1/a04v7n1.pdf.>. 


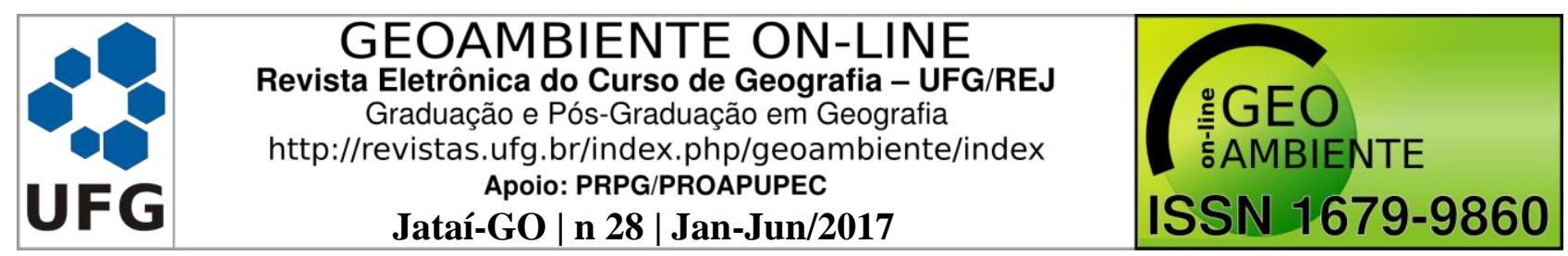

Acesso: 04 ago. 2015.

MARANDINO, M. Museus de ciências como espaços de educação: In: Museus : dos gabinetes de curiosidades `a museologia moderna. Belo Horizonte: Argumentum. p. 165-176. 2005.

OLIVEIRA, E.R. Parâmetros científicos de avaliação do estado de conservação de espécimes de taxidermia artística para museus e coleções: aplicação do método no acervo do Museu de Ciências Naturais Carlos Ritter. Monografia, Universidade Federal de Pelotas, RS, 2010. Disponível: <https://museologiaufpel.files.wordpress.com/2010/09>. Acesso: 10 set. de 2015. QUEIROZ, R.M.; TEIXEIRA, H.B.; VELOSO, A.S.; TERÁN, A.F. QUEIROZ, A.G. A caracterização dos espaços não formais de educação científica para o ensino de ciências. Disponível: <www.nutes.ufrj.br/abrapec/viiienpec/resumos/R1579-2.pdf>. Acesso: 19 nov. 2015.

SANTOS, M.C.T.M. Processo museológico e educação: construindo um museudidáticocomunitário. Cadernos de Sociomuseologia 7, Lisboa: ULHT, 1996.

SEPÚlVEDA, L. Ação Educativa em Museus. Apostila do $5^{\circ}$ módulo do curso Dinamizando o Museu-Coordenação do Sistema Estadual de Museus - PR. Apostila do $4^{\circ}$ módulo do curso Dinamizando o Museu-Coordenação do Sistema Estadual de Museus - PR, 2003.

TERÁN, A.F; SANTOS, S.C.S. O uso da expressão espaços não formais no ensino de ciências. Revista Amazônica de Ensino de Ciências 11, p. 01-15, 2013. 